\title{
Results of a 1 year Special Action Project for the Elimination of Leprosy (SAPEL) in poorly accessible areas of Akwa Ibom State, Nigeria
}

\author{
BASSEY EFFIONG EBENSO \\ The Leprosy Mission, PMB 01048, Gusau, Zamfara State, Nigeria
}

Accepted for publication 15 October 1998

\begin{abstract}
Summary This article reports the outcome of a Special Action Project for the Elimination of Leprosy (SAPEL), including the implementation of multidrug therapy (MDT) in difficult situations in Akwa Ibom State in Nigeria. Twenty-two fishing villages and five communities in areas of gully erosion participated in the project from August 1996 to September 1997. Seven new cases were detected and treated with MDT. Twenty-one out of 22 defaulters examined resided in the mainland part of the project area and not in the fishing villages. Considerable difficulties were encountered with regard to the exorbitant cost of transport, physical attacks on the teams and the lack of reliable information on population figures for the project area. The discussion includes attention to the cost-effectiveness of the SAPEL approach under the conditions described and the need to develop better monitoring of treatment and community participation in poorly accessible areas.
\end{abstract}

\section{Introduction}

For over 6 decades, efforts to control leprosy as a public health problem in Akwa Ibom State, southeast Nigeria, were limited to the mainland regions. Problems of inaccessibility and poor communication prevented penetration of areas of severe gully erosion, the creeks and fishing islands scattered around the state. For these reasons, Akwa Ibom State leprosy control programme adopted the WHO Special Action project for the Elimination of Leprosy (SAPEL) $^{1}$ initiative in 1995 , to extend multidrug therapy (MDT) to leprosy patients living in poorly accessible areas of the state; and to verify a suspicion that the majority of defaulting patients hide in the fishing communities. This paper relates the outcome of MDT implementation in 27 villages in three Local Government Areas or districts, in Akwa Ibom State. This is the first time any kind of leprosy control has been carried out in the 22 fishing communities that participated in the SAPEL project. This account covers the period from August 1996 when the project commenced to December 1997 when multibacillary (MB) patients were discharged from MDT.

\section{BACKGROUND}

Akwa Ibom State, one of the 36 states of the Federal Republic of Nigeria, is situated on the 
southeastern corner of the country and covers a land area of about $5862 \mathrm{~km}^{2}$. The shape of the state approximates that of a triangle. Its boundaries are Rivers State and Abia State to the west; Cross-River State to the east; and the Atlantic Ocean to the south. The 1997 estimated population of the state is 2.79 million, projected from 1991 census figure of 2.36 million using an annual growth rate of $2 \cdot 83 \%$. $^{2}$ The majority of the population are rural dwellers. Two main ethnic groups, namely the Annangs and the Ibibios, inhabit the state. The predominant occupations are agriculture and fishing.

The climate of the state is described as tropical rainy type. There are two distinct seasons: the dry season from November to March during which the cool and dust laden Harmattan wind blows, and the rainy season from April to October. On the basis of terrain and landform types, ${ }^{3}$ two major geomorphic regions are identified within Akwa Ibom State. These are the flat coastal plain regions characterized by rivers and ox-bow lakes in the southern part of the state, and the high rising dissected regions characterized by ravines and steep-sided hills in the northern part of the state.

Administratively, the state is divided into 31 Local Government Areas (LGAs) with population range of 56,000-235,000 people. For purposes of health care delivery, the state is divided into three health zones comprising about 10 LGAs per zone. The Local Government Area is the operational level of primary health care (PHC) implementation in Nigeria, ${ }^{4}$ including leprosy control. There are 230 health facilities offering primary care in Akwa Ibom State. $^{5}$ Thirty-six (16\%) of these 230 health facilities are leprosy clinics offering MDT services. Furthermore, 11 out of the 36 leprosy clinics are vertical (leprosy-only) clinics. The remaining 25 leprosy clinics operate as semi-integrated clinics within PHC facilities and are run by specialized leprosy staff. General health personnel attached to these 25 semi-integrated leprosy clinics are yet to be functionally involved in leprosy control activities.

\section{BRIEF LEPROSY SITUATION}

In 1926, the Scottish Presbyterian Mission built Nigeria's first leprosy hospital in Itu LGA in the north of Akwa Ibom. The Itu Hospital played a pioneering role in leprosy research and treatment during the use of Chaulmoougra oil and dapsone in the treatment of leprosy. Unfortunately, this hospital now lies in ruins after the Nigerian Civil war of 1967-1970. A sister-hospital established in 1932 by Qua Iboe Fellowship, Belfast, and situated in Etinan LGA, south of Akwa Ibom, continued the functions of Itu Hospital. The Qua Iboe Church Leprosy Hospital serves as the present day referral centre for leprosy control in Akwa Ibom State. For reasons of poor communication and inaccessibility, efforts to control leprosy as a public health problem in the state using dapsone monotherapy were limited to the mainland parts. The creeks and fishing islands were difficult to penetrate without canoes.

The WHO/MDT was introduced in the state in 1982. By December 1993, Akwa Ibom State had achieved $100 \%$ MDT coverage of clinics situated in the mainland parts of the state. Following the implementation of MDT, the registered prevalence of leprosy in Akwa Ibom decreased from about 2000 patients in 1982 to 225 by October 1997. The MDT completion rates in 1996 were poor in both MB (60\%) and paucibacillary (PB) (73\%) patients. The grade 2 disability rate amongst new cases in 1996 was $16.8 \%$. $^{6}$ The MDT completion cohort and disability figures for the end of 1997 were not available when this report was written. 
SITE OF THE PROJECT

Akwa Ibom State adopted the SAPEL initiative in December 1995 to extend MDT services to poorly accessible communities in a total of 12 LGAs in state. Because of the scattered nature of fishing communities and the vastness of the area covered by the 12 LGAs, extension of MDT to poorly accessible communities was to be executed in phases. Three LGAs served as sites for the first phase of the project, namely, Ikono and Itu LGAs in the north and Uruan LGA in the east central part of the state. Ikono LGA lies within the high rising regions characterized by gully erosions and ravines that make road transportation difficult throughout the year. On the other hand, Uruan LGA lies within the flat coastal plains traversed by rivers and lakes that are only accessible by canoe. Itu LGA lies between the two land form regions.

The population of the three LGAs is approximately 400,000. The 1996 end-of-year prevalence of leprosy in the project area was $2 \cdot 5 / 10,000$ population. ${ }^{6}$ There was a total of 72 defaulters in Akwa Ibom State in January 1996. Uruan, Itu and Ikono LGAs contributed 59 $(82 \%)$ of the 72 defaulters. In addition to extending MDT to the project area, the project attempted to verify the suspicion advanced by the State leprosy control of ficer that the majority of defaulters from the mainland hide in the fishing islands of the project area.

\section{Materials and methods}

A SAPEL project to extend MDT to poorly accessible communities in Akwa Ibom State commenced in August 1996 and lasted until September 1997. Leprosy control supervisors of the project LGAs selected a total of 29 villages, but 27 of them participated in the project. Based on WHO inclusion criteria, five out of the 27 villages that participated were purposely selected from areas of gully erosion, whereas the remaining 22 villages were selected from fishing communities, as they were not covered by health services. No form of leprosy control service had ever been carried out in the 22 fishing communities. The tribal population of these fishing communities is also nomadic in lifestyle, migrating from island to island at least 8 months of the year in search of fertile fishing grounds. The project was therefore scheduled to start in the month of August when the rains are heaviest and the fishermen remain in their homes. Letters explaining the reasons for the project were addressed to community leaders, soliciting their cooperation and participation in the project.

The objectives of the project were: (i) to determine the prevalence of leprosy in the selected area, (ii) to verify a suspicion that the majority of defaulting patients hide in the fishing islands and (iii) to ensure that patients enjoyed uninterrupted MDT service in the difficult situations of the project area by involving village heads in control activities.

The project was subdivided into two parts; (a) community surveys and defaulter tracing to achieve objectives (i) and (ii); and (b) 1-year follow-up period, to achieve objective (iii). A team of eight people comprising two medical officers (MOs) and six LGA leprosy supervisors participated in the project. The leprosy supervisors selected had more than 15 years of field experience in leprosy control, while the MOs [one of who is the author and the other was the State Leprosy Control Officer (SLCO)] had 4 years of experience. The SLCO participated in the project only during the survey, while the author and the six leprosy supervisors took part in the surveys and the follow-up of the patients detected, but on a part-time basis (combining the project with regular control activities). The team penetrated the riverine areas by use of canoes and the high rising areas by the use of motor cycles. 
Prior to the community surveys, the supervisors trained village leaders in the diagnosis of leprosy, availability and efficacy of MDT and the advantages of early detection, by guided discussions lasting about $45 \mathrm{~min}$. After the training, a house-to-house survey of the community took place, with the active participation of the village heads in the examination of people present. Diagnosis of a case of leprosy and classification were carried out by clinical examination following the WHO guidelines. ${ }^{7}$ The MOs re-examined suspect cases presented by the village heads. Confirmed cases were treated with MDT without delay.

During the follow-up period, village heads monitored the treatment of confirmed cases until the supervisor's next visit. The village heads were given MDT blister calendar packs lasting up to 4 months to ensure that the patients got an uninterrupted supply of drugs. The supervisors returned to replenish the MDT blister calendar packs of village leaders and chart the progress of patients every 2 months.

Only the supervisors carried out defaulter tracing during the project. MOs did not take part in the defaulter tracing. At least two visits for each defaulter were carried out before most of them were found and examined.

At the start of the project, cure was defined as completion of fixed duration WHO MDT. PB patients were required to take six doses within 9 months. MB cases were expected to take 24 doses of MDT within 36 months before they were released from treatment (RFT). However, the adoption by Nigeria in December 1997 of the WHO recommendations ${ }^{8}$ for shortening the duration of treatment for MB cases from 24 doses to 12 doses of MB-MDT led to a revision of the RFT protocol for MB patients.

At the expiration of the project in September 1997, responsibility for funding and supervision of MDT activities in the project area was transferred to The Leprosy Mission, the ILEP Coordinator of leprosy control in Akwa Ibom State.

\section{Results}

\section{CASE FINDING}

Twenty-seven villages took part in the project. Two villages involved in inter-communal conflict did not participate. The surveys lasted for 30 days. A total of 6129 people from 768 households was examined. This population comprised 3621 children and 2508 adults; see Table 1 for details. Table 2 shows the age, classification, disability grades, and treatment outcomes of patients. Seven new patients (four PB and three MB) were detected during the survey. Only one child was detected. All four PB patients had single, active lesions. All seven patients took their treatment regularly. By December 1997, PB patients had been RFT after taking six doses of MDT. The MB patients had received at least 12 doses of MDT and were

Table 1. Distribution of examined population by age and sex

\begin{tabular}{lcccc}
\hline & $0-14$ years & $15+$ years & Total & $\%$ \\
\hline Male & 1743 & 1712 & 3455 & $56 \cdot 4$ \\
Female & 1874 & 796 & 2674 & $43 \cdot 6$ \\
Total & 3621 & 2508 & 6129 & 100 \\
$(\%)$ & $(59 \cdot 1)$ & $(40 \cdot 9)$ & $(100)$ & - \\
\hline
\end{tabular}


Table 2. Classification, disability grade and age of new patients detected

\begin{tabular}{lcccc}
\hline Sex & Age (years) & Classification & Disability grade & Treatment outcome \\
\hline M & 14 & PB & 0 & RFT \\
M & 22 & MB & 0 & RFT \\
F & 33 & PB & 0 & RFT \\
M & 35 & PB & 0 & RFT \\
M & 45 & MB & 0 & RFT \\
F & 45 & PB & 0 & RFT \\
F & 50 & MB & 0 & RFT \\
\hline
\end{tabular}

RFT following a 1997 WHO recommendation ${ }^{8}$ for treating MB patients with 12 doses of MDT.

DEFAULTER RETRIEVAL

Table 3 shows the outcome of defaulter retrieval during the project. Fifty-two out of 59 defaulters were selected for retrieval. Seven patients were excluded due to incomplete records. Only 22 of the 52 defaulters on the mainland register could be traced and examined. Some of the remaining 30 patients had either died or left the control area to go to neighbouring states looking for jobs. Only one of the 22 defaulters examined was resident in the fishing community. The remaining 21 defaulters were found on the mainland parts of the project area. The reason for defaulting given by the majority of patients was the belief that their disease was cured. After careful consideration by the project team, all 22 patients were RFT as their skin lesions were inactive. By December 1996, only four defaulters were on the register. These were patients living in the two warring communities that did not participate in the project.

\section{LIMITATIONS AND DIFFICULTIES ENCOUNTERED DURING THE SURVEY}

(i) The total population listed in the case finding section above is the number of people

Table 3. Outcome of defaulter retrieval

\begin{tabular}{|c|c|c|}
\hline Category & Number of patients & Percentage \\
\hline Number of defaulters before tracing & 52 & 100 \\
\hline Number RFT (cured) & 22 & $42 \cdot 3$ \\
\hline Number re-admitted for MDT $=$ & 0 & 0 \\
\hline Number who died & 6 & $11 \cdot 5$ \\
\hline Number living in warring communities & 4 & $9 \cdot 6$ \\
\hline Number who left control area to neighbouring states ${ }^{a}$ & 12 & $23 \cdot 1$ \\
\hline Number labelled out of control (no information available) ${ }^{\mathrm{a}}$ & 8 & $15 \cdot 4$ \\
\hline
\end{tabular}

\footnotetext{
${ }^{\mathrm{a}}$ These categories of patients were removed from the register at the end of 1996. Number of defaulters in the project area at the end of $1996=4$. Number of defaulters in Akwa Ibom State by 31 December $1997=7$.
} 
examined during the survey. Official (enumerated) population figures of the 27 communities in the project area were not available from the of fice of statistics. The population estimates of 23,640 given by village leaders were considered unreliable by the survey team, judging from the number of houses and people observed during the surveys.

(ii) The survey team was attacked and molested by youths who believed the team were spies from a neighbouring, rival community.

(iii) Under the local conditions described, the cost of water transportation that consumed approximately $25 \%$ of the total project funds $(\$ 12,179)$ was exorbitant, perhaps due to the scarcity of petrol used to power boats used during the project and because most of the fishing villages were out of routes commonly travelled by commercial water transport operators.

(iv) The nomadic lifestyle of the fishermen, who migrate in search of fertile fishing grounds, made follow-up of one patient difficult.

\section{Discussion}

It is noteworthy that all seven new patients were detected at very early stages and without disabilities. The compliance of patients to MDT without default emphasizes the positive role played by the village leaders in leprosy control on difficult situations of the project. This re-affirms previous reports by Ahmed and El Tahir $^{9}$ from Sudan, and Schäffer and Gakaitangou $^{10}$ from Chad.

The discovery of 21 of the 22 examined defaulters on the mainland part of the project area is a departure from the expectations of the project team. This result disproves the suspicion that the majority of defaulters hide in fishing islands and questions the practice of routine defaulter tracing in the mainland prior to SAPEL.

The detection of only seven new patients during the project should be interpreted with caution. On the one hand, the few numbers of patients detected appears to suggest that the backlog of untreated or hidden cases in the project area may be smaller than the backlog of untreated cases in other parts of the state which are easily accessible, mainland communities. These easily accessible, mainland communities contributed 112 (94\%) of new cases detected in 1996 and 125 (100\%) new cases detected in 1997 in Akwa Ibom State.

On the other hand, the detection of seven new cases in a population of 6129 implies an incidence rate of approximately one case per 1000 people examined, suggesting that neglect of such populations could, in future, contribute a significant proportion of new cases detected and may affect the attainment of sustenance of the WHO elimination target of prevalence of less than one case/10,000 population in Akwa Ibom region. The author is, however, unable to draw definite conclusions from this low number of new cases, as the project area represented only $25 \%$ of poorly accessible regions of Akwa Ibom State.

\section{Recommendations}

Judging by the small number of patients detected in the fishing communities, the limitation posed by exorbitant transport costs and the scarcity of funds to carry out such projects in developing countries, the author recommends that future leprosy control work in difficult situations in Akwa Ibom State give priority attention to (i) LGs in the northern part of the state where leprosy is reported to be hyper-endemic ${ }^{11}$ and the cost of transportation is affordable 
using motorcycles; (ii) better monitoring of patient treatment and prompt retrieval of absentees to prevent the occurrence of alarming numbers of defaulters; (iii) intensive and continuous community education using the radio to encourage early case detection and (iv) active community participation in the planning and implementation of MDT projects to ensure sustainability.

\section{Acknowledgements}

This project was one of several SAPEL projects around the world supported by grants from the World Health Organisation. The author is grateful to all who were involved in the project, in particular Dr U. D. Okpongete, whose pioneering effort led to the execution of this project. The technical guidance of Dr N. Chitimba and Dr T. O. Sofola is gratefully acknowledged. The author thanks Miss J. L. Hunter and Dr O. Ogbeiwi for reading the manuscript.

\section{References}

1 WHO. Action Programme for the Elimination of Leprosy. Leprosy Elimination Campaign (LEC) and Special Action Projects for the Elimination of Leprosy (SAPEL). Questions and answers. World Health Organisation, Geneva, 1997. WHO/LEP/97.3.

2 Annual Abstract of Statistics 1996 edition. Federal Of fice of Statistics, Lagos, Nigeria, pp 27-29.

${ }^{3}$ Peters SW, Iwok ER, Uya OE. Akwa Ibom State-the land of promise-a compendium. GABUMOH Publishing Company. Yaba, Lagos, Nigeria, 1994: 239-244.

4 WHO. Local government focused acceleration of primary healthcare: the Nigerian experience. Report of a WHO review. WHO, Geneva, 1992: 3.

5 Akwa Ibom State Ministry of Health Statistics on Primary Health Care, 1995.

6 Annual Report. Akwa Ibom State Leprosy Control Programme, 1996.

7 WHO. A guide to elimination of leprosy as a public health problem, 1st edition. WHO/LEP/95.1, 1995: 15-21.

8 WHO. Final draft of WHO Expert Committee on Leprosy, 7th Report, 1997: 17-18.

9 Ahmed KM, El Tahir MS. Role of village leaders in the implementation of multidrug therapy for leprosy, Sudan-a pilot study in the Angasana Hills. Lepr Rev, 1996; 67: 39-46.

${ }^{10}$ Gakaitangou F, Schäffer J. Comment: implementing multidrug therapy in areas not covered by the health services-some experiences from Chad. Lepr Rev, 1997; 68: 90-91.

11 Brightmer MI. New cases of leprosy in the Cross River Region, Nigeria. Lepr Rev, 1990; 61: 273-281. 